www.jmscr.igmpublication.org

Impact Factor (SJIF): 6.379

Index Copernicus Value: 79.54

ISSN (e)-2347-176x ISSN (p) 2455-0450

crossrefDOI: https://dx.doi.org/10.18535/jmscr/v6i9.144

Journal Of Medical Science And Clinical Research

IGM Publication

An Official Publication of IGM Publication

\title{
Ultrasound Evaluation of Painful Shoulder Joints
}

\author{
Authors \\ Dr Basanta Manjari Swain ${ }^{1}$, Dr Pradipta Kumar Mishra ${ }^{2}$ \\ ${ }^{1}$ Associate Professor, Dept. of Radiodiagnosis, SCB Medical College \\ Email: bmswain8@gmail.com, Phone: 8249228709 \\ ${ }^{2}$ Senior Resident, Dept. of Radiodiagnosis, SCB Medical College \\ Email: pkradiology2016@gmail.com, Phone: 9861156431
}

\section{Introduction}

The shoulder joint is a ball and socket joint without any fixed axis of rotation, which has a wide range of motion in multiple planes; hence stability is compromised for mobility. To compensate for the unstable bony anatomy the shoulder is protected anteriorly, posteriorly and superiorly by a capsule and the tendons that form the rotator cuff. The tendon is subject to "wear and tear" during the day to day activities. Spectrum of etiologies that can give rise to shoulder pain are acute trauma to a gamut of degenerative disorders associated with impingement syndrome. Shoulder pain is one of the most common complaints encountered in orthopedic practice and often leads to considerable disability. There are various causes of a painful shoulder, but periarticular soft tissue lesions involving tendons and bursae are the most common and are often associated with chronic impingement of the rotator cuff on the anterolateral margin of the acromion. Even though a large amount of clinical tests used for the diagnosis of painful shoulder are considered accurate in determining the location of the periarticular lesions, these entities may be difficult to differentiate by physical examination. Clinical diagnosis have low accuracy in comparison with $\operatorname{arthroscopy}^{[1][3]}$.

The lesions of the rotator cuff are common cause of shoulder pain and dysfunction. Cuff strain, impingement syndrome, rotator cuff tears make up a group of lesions that produce shoulder pain. It is clinically difficult to differentiate between these diagnosis and distinguish cuff problems from other conditions like Glenohumeral instability. Rotator cuff injury is a different spectrum, which is of the nature of chronic injury because of the intrinsic nature of the musculo-tendinous and osseo-tendinous part of the Rotator cuff and the anatomically narrow sub acromial space. Hence, it is the commonest musculoskeletal ultrasound examination request. Improvement in the resolution of ultrasound machines, redefined technique and better understanding of the pathology have contributed to its high accuracy in the diagnosis of rotator cuff pathology. Repetitive active and passive forces render these tendons susceptible to degeneration leading to swelling of the tendon and a minor degree of subluxation. The space between the humeral head and the acromion is sufficiently restricted that mild swelling of the 
interposed tendon with or without minor superior subluxation of the humeral head leads to impingement syndrome.

High resolution ultrasound is noninvasive, less expensive and non-ionizing modality with good sensitivity in detecting both rotator cuff and nonrotator cuff disorder. It serves as a complementary role to magnetic resonance imaging of the shoulder. The reported accuracy, sensitivity and specificity of high resolution ultrasound in the detecting of any tear, whether partial or full thickness are all greater than $90 \%{ }^{[4]}$.

High resolution ultrasound can also reveal the presence of other abnormalities that may mimic rotator cuff tear at clinical examination, including Tynosynovitis, Tendinosis, Calcific tendinosis, Subacromial-Subdeltoid bursitis, Greater tuberosity fracture etc. Magnetic Resonance imaging and Ultrasonography have replaced arthrography for evaluating the integrity of the rotator cuff. Magnetic Resonance arthrography is used for instability.

MRI has become the "gold standard" for detecting both subtle and obvious internal derangement and assessing overall joint structure. MRI is an excellent modality because of its multiplanar capability. Finding a correlation between symptoms and images is a challenging task and is essential to ensure that the imaging findings explain the symptoms and can be used to adjust the therapy.

MRI is reliable technique for the evaluation of rotator cuff tendons; previous low power magnet MRI's provided only a static evaluation of the shoulder joint and indirectly suggested the diagnosis of subacrominal impingement. Whereas, recent super conductive magnets make it possible to do a dynamic evaluation of the shoulder joint to some extent. Over the last two decades musculoskeletal USG has established itself as a versatile imaging modality in the fields of radiodiagnosis, sports medicine and rheumatology. It has gained its rightful place in literature along with MRI. Cost effectiveness and ready availability are its biggest advantages in several clinical settings. The real time capability of ultrasound in conducting dynamic studies in areas like the shoulder is a very big asset. It helps to do quick comparison with the contra-lateral side, which is of great help in many difficult situations. It has its own limitations such as high operator dependency, long learning curve and problems of anisotropy. It has limited utility in evaluation of labral, rotator cuff interval, and in demonstrating subtle bony lesions. USH has its own limitations such as high operator dependency, long learning curve and problems of anisotropy. It has limited utility in evaluation of labral, rotator cuff interval lesions and in demonstrating subtle bony lesions. In our study of 49 patients with shoulder joint pain, with a clinical suspicion of rotator cuff injuries were subjected to USG and MRI of the shoulder joint. Our aim was to show that ultrasound examination was as effective to MRI, in the evaluation of shoulder pain, especially in cases of rotator cuff injuries.

\section{Aims and Objectives}

* Assessment by Ultrasound as the first time of imaging modality as compared to MRI in patients with shoulder pain.

* Comparing the accuracy of Ultrasonography in Rotator cuff pathologies by comparing its findings with those of mangetic resonance imaging performed subsequently on the same patient.

* To delineate pitfalls during image interpretation and limitation of USG and MRI.

\section{Methodology}

This prospective study evaluating patients with shoulder pain by Ultrasound and MRI.

\section{Source of data}

The study was conducted in the Department of Radiodiagnosis, SCB Medical College, Cuttack. Through clinical history \& clinical examination were done prior to USG and MRI of both shoulders. 


\section{Inclusion criteria}

- Age $>40$ yrs.

- History of pain in either shoulder joint.

- History of trauma (trivial).

- Clinically suspected to have a rotator cuff injury (full thickness or partial thickness tears), biceps tendon injury, or calcific tendinitis.

\section{Exclusion criteria}

- Clinically suspected cases of instability.

- Known cases of Rheumatoid arthritis

- Previous surgery or prosthesis of shoulder.

- Patients with pace markers, metal implants in their bodies.

Study Period: March 2017 to September 2018.

Study Design: Prospective study.

Ultrasound examination of the shoulder: The examination on the affected shoulder was carried out on a Philips HD 7, with a high frequency linear transducer of $6-12 \mathrm{MHz}$. The rotator cuff tendons and muscles were examined in various positions, the ACJ and the posterior aspect of the joint was also examined. Dynamic examinations of the shoulder were also carried out. Comparison of the opposite shoulder was also done.

MRI of the affected shoulder: The MRI examination as performed on a with a GE Signa HDX MR machine with a 1.5 tesla field strength magnet. Coil centered over the affected shoulder with the patient in supine position. Multiplanner images were obtained in the axial, oblique coronal and oblique sagittal planes.

\section{The sequences used were}

- Short T1 inversion recovery (STIR) in the plane, a slice thickness of $3 \mathrm{~mm}$, a FOV of $150 \mathrm{~mm}$ and TR/TE - 7913/170.

- Proton density images in the oblique coronal plane, a slice thickness of $3 \mathrm{~mm}$, a FOV of $140 \mathrm{~mm}$ and TR/TE - 4500/30.

- T2 weighted images in the oblique coronal plane, a slice thickness of $3 \mathrm{~mm}$, a FOV of $140 \mathrm{~mm}$ and TR/TE - 4375/100.
- $\quad$ T2 (SPAIR) images in the oblique coronal plane, a slice thickness of $3 \mathrm{~mm}$, a FOV of $140 \mathrm{~mm}$ and TR/TE - 4000/50.

- Proton density images in the oblique sagittal plane, a slice thickness of $3 \mathrm{~mm}$, a FOV of $140 \mathrm{~mm}$ and TR/TE - 4500/30.

- Short T1 inversion recovery (STIR) images in the oblique sagittal plane, a slice thickness of $3 \mathrm{~mm}$, a FOV of 140 $\mathrm{mm}$ and TR/TE - 3443/60.

Statistical Analysis: All the data were expressed in percentages. The findings of the clinical examination, USG and MRI findings were correlated followed by analysis of the present study by comparing with previous similar studies from various literatures. Then summary and conclusions were drawn as regard to accuracy of USG in evaluating Rotator cuff injuries.

\section{Observations \& Results}

\begin{tabular}{|l|c|}
\hline \multicolumn{2}{|l|}{ Table 1 Sex Distribution } \\
\hline Male & Female \\
\hline $\mathbf{2 8}(\mathbf{5 7 . 1 \%})$ & $\mathbf{2 1 ( 4 2 . 9 \% )}$ \\
\hline $\mathbf{n = 4 9}$ & \\
\hline
\end{tabular}

Table 2 - Age Distribution

\begin{tabular}{|l|c|c|}
\hline $40-50$ Years & $50-60$ Years & $>60$ Years \\
\hline $9(18.5 \%)$ & $19(38.7 \%)$ & $21(42.8 \%)$ \\
\hline$n=49$ &
\end{tabular}

\begin{tabular}{|l|c|}
\hline Table 3 - Affected Hand \\
\hline Right & Left \\
\hline $\mathbf{3 4}(69.4 \%)$ & $\mathbf{1 5}(\mathbf{3 0 . 6 \% )}$ \\
\hline $\mathbf{n}=\mathbf{4 9}$, , dominant hand of all patients was right \\
\hline
\end{tabular}

\begin{tabular}{|l|c|}
\hline \multicolumn{2}{|l|}{ Table 4 Diabetes History } \\
\hline Present & Absent \\
\hline $\mathbf{1 2}(\mathbf{2 4 . 4 \% )}$ & $\mathbf{3 7}(\mathbf{7 5 . 6 \%})$ \\
\hline $\mathbf{n}=\mathbf{4 9}$ & \\
\hline
\end{tabular}

Table 5 - Physical Examination Findings

\begin{tabular}{|l|l|l|}
\hline Test & Positive & Negative \\
\hline Tenderness & $\mathbf{1 0}(\mathbf{2 0 . 4 \% )}$ & $\mathbf{3 9}(\mathbf{7 9 . 6 \%})$ \\
\hline Restriction of Movement & $\mathbf{2 9}(\mathbf{5 9 . 1 \%})$ & $\mathbf{2 0}(\mathbf{4 0 . 9 \%})$ \\
\hline Neer's Test & $19(38.7 \%)$ & $\mathbf{3 0}(61.3 \%)$ \\
\hline $\mathbf{n}=49$ & \\
\hline
\end{tabular}


Table 6 - USG Findings (Tendon)

\begin{tabular}{|c|c|c|c|c|c|}
\hline Tendons & Full Tear & Partial Tear & Tendinosis & I.S Tear* & Normal \\
\hline Subscapularis & (0 (0\%) & $3(6.1 \%)$ & $2(4.1 \%)$ & $0(0 \%)$ & $44(89.8 \%)$ \\
\hline Supraspinatus & $4(8.2 \%)$ & $22(44.8 \%)$ & $10(20.4 \%)$ & $\mathbf{0}(\mathbf{0 \%})$ & $13(26.5 \%)$ \\
\hline Infraspinatus & $\mathbf{0}(0 \%)$ & $\mathbf{0}(\mathbf{0 \%})$ & $\mathbf{0}(0 \%)$ & $\mathbf{0}(0 \%)$ & $49(100 \%)$ \\
\hline Teres Minor & 0(0\%) & (0) (0\%) & $0(0 \%)$ & 0(0\%) & $49(100 \%)$ \\
\hline Biceps Tendon & $\mathbf{0}(0 \%)$ & $0(0 \%)$ & $0(0 \%)$ & $0(0 \%)$ & $49(100 \%)$ \\
\hline
\end{tabular}

\begin{tabular}{|c|c|c|c|c|c|}
\hline Tendons & Full Tear & Partial Tear & Tendinosis & I.S Tear* & Normal \\
\hline Subscapularis & $\mathbf{0}(\mathbf{0 \%})$ & $4(8.1 \%)$ & $2(4.1 \%)$ & 0 (0\%) & $43(87.8 \%)$ \\
\hline Supraspinatus & $4(8.2 \%)$ & $24(48.9 \%)$ & $10(20.4 \%)$ & $0(0 \%)$ & $11(22.4 \%)$ \\
\hline Infraspinatus & $0(0 \%)$ & $\mathbf{0}(0 \%)$ & 0 (0\%) & $0(0 \%)$ & $49(100 \%)$ \\
\hline Teres Minor & $0(0 \%)$ & $0(0 \%)$ & $0(0 \%)$ & $0(0 \%)$ & $49(100 \%)$ \\
\hline Biceps Tendon & $0(0 \%)$ & 0(0\%) & 0(0\%) & $0(0 \%)$ & $49(100 \%)$ \\
\hline
\end{tabular}

\begin{tabular}{|c|c|c|c|c|}
\hline \multicolumn{2}{|l|}{ TEST } & \multicolumn{2}{|c|}{ MRI } & \multirow{3}{*}{$\begin{array}{c}\text { TOTAL } \\
25\end{array}$} \\
\hline & & + & - & \\
\hline \multirow{2}{*}{ ט מש D } & + & $23(46.9 \%)$ & $2(4.2 \%)$ & \\
\hline & - & $5(10.2 \%)$ & $19(38.7 \%)$ & 24 \\
\hline \multicolumn{2}{|l|}{ TOTAL } & 28 & 21 & 49 \\
\hline \multirow{2}{*}{\multicolumn{5}{|c|}{$\begin{array}{c}\mathrm{n}=49 \\
\text { TABLE } 9 \text { - FULL TEAR USG AND MRI }\end{array}$}} \\
\hline & & & & \\
\hline \multirow{2}{*}{\multicolumn{2}{|c|}{ TEST }} & \multicolumn{2}{|c|}{ MRI TEAR } & \multirow[t]{2}{*}{ TOTAL } \\
\hline & & + & - & \\
\hline \multirow{2}{*}{ U מ D } & + & $4(8.1 \%)$ & $0(0 \%)$ & 4 \\
\hline & - & $\mathbf{0 ( 0 \% )}$ & $45(91.9 \%)$ & 45 \\
\hline \multicolumn{2}{|c|}{ TOTAL } & 4 & 45 & 49 \\
\hline
\end{tabular}

\begin{tabular}{|c|c|c|c|c|}
\hline \multirow{2}{*}{\multicolumn{2}{|c|}{ TEST }} & \multicolumn{2}{|c|}{ MRI TEAR } & \multirow{3}{*}{$\begin{array}{c}\text { TOTAL } \\
19\end{array}$} \\
\hline & & + & - & \\
\hline \multirow[b]{2}{*}{ ש מ מ } & + & $18(36.7 \%)$ & $1(2.0 \%)$ & \\
\hline & - & $13(26.5 \%)$ & $17(34.8 \%)$ & 30 \\
\hline TOTAL & & 31 & 18 & 49 \\
\hline
\end{tabular}

\section{Conclusion}

1) Ultrasound and magnetic resonance imaging are both very sensitive techniques for diagnosis of rotator cuff abnormalities.

2) Ultrasonography can be used as a primary method owing to its fast procedure and affordable cost.

3) USG is not as sensitive as MRI in evaluating labral and capsular pathologies.

4) MRI can be used as an additional method providing clarification and more detailed information on joint deformations with the possibility of $3 \mathrm{D}$ reconstruction and description of structural changes of connected areas.

\section{Bibliography}

1. Naredo E, Aguado P, De Miguel E, Uson $\mathrm{J}$, et al. Painful shoulder comparison of physical examination and ultrasonographic findings. Ann Rheum Dis 2002; 61:132 136.

2. Peterson JJ. Shoulder injections. Peterson JJ, Fenton DS, Czervionke LF eds. ImageGuided Musculoskeletal Interventions. $1^{\text {st }}$ 
ed. Philadelphia, Pa: Saunders Elsevier; 2008: 9 - 40.

3. J Norregaard, $\mathrm{M} \mathrm{R}$ Krogsgaard, $\mathrm{T}$ Lorenzen, E M Jensen. Diagnosing patients with longstanding shoulder joint pain. Ann Rheum Dis 2002; 61: 646 - 649.

4. Seltzer SE, Finberg HJ, weissman BN, Kido DK, Collier BD. Arthrosonography: Gray-scale ultrasound evaluation of the shoulder. Radiology 1979; 132: 467 - 8.

5. Neer CS II. Impingement lesions. ClinOrthop 1983; 173: 70 - 77.

6. MK Mugde, V Wood, and GK Erykman. Rotator cuff tears associated with osBacromiale. J Bone joint Surg. 1984; 66: $427-429$.

7. Crass JR. USG of the Rotator cuff. Radiographics. 1985; 5: 941 - 953.

8. William D. Middleton, Gerald Edelstein, William R. Remus, G. Leland Melson, William G. Totty, William A. Murphy. Sonographic Detection of rotator cuff tears. AJR 1985 Feb; 144: 349 - 353.

9. Middleton WD. Pitfalls of Rotator cuff sonography. AJR. 1986; 146: 555 - 560.

10. Brandt TD, Cardone BW, Grant TH, et al. Rotator cuff sonography: A Reassessment. Radiology. 1989; 173 (2): 323 - 7. 